\title{
The Effect of Student Learning Strategies on Performance and Carrier Development: The Case of University for Development Studies, Wa Campus
}

\author{
Kanlisi Kaba Simon \\ Department of Governance and Development Management, Faculty of Planning and Land Management, University for Development Studies \\ Wa Campus, Wa, Ghana
}

Email address:

skanlisi@uds.edu.gh

To cite this article:

Kanlisi Kaba Simon. The Effect of Student Learning Strategies on Performance and Carrier Development: The Case of University for Development Studies, Wa Campus. Education Journal. Vol. 5, No. 6, 2016, pp. 174-182. doi: 10.11648/j.edu.20160506.18

Received: October 24, 2016; Accepted: November 5, 2016; Published: December 23, 2016

\begin{abstract}
In an increasingly global environment bedeviled with various social, economic and environmental challenges, the quest for education that guarantees employability has become paramount. The extent to which higher educational institutions' curriculum responds to employability has been questioned by industry, parents and students. This study explored the learning strategies of 500 undergraduate students in higher education in the Wa Campus of the University for Development Studies, Tamale, Ghana and the effect on their performance and carrier aspirations. Twenty lecturers and managers of three development organisations that receive students on internship were also purposively selected. The study revealed that generally, the immediate objective of excelling in examinations has been the driving force of students' choice of a learning strategy throughout the levels of their undergraduate studies. The results also gave an indication that students tended to adopt specific learning strategies because of impressions they have built regarding the nature of course delivery by instructors/teachers/lecturers. Even though almost all the undergraduate programmes' curriculum involve practical work including internships in addition to expectations that as students graduate to levels 300 and 400 , they will begin to apply their knowledge and network more, many more of them rather prefer memorization which they claimed increases their chances of excelling academically. The study concluded that to ensure that students are able to make a full contribution to society, institutions of higher learning need to create more opportunities for students and academia to interface with industry in order to boost students' self-confidence and to re-orient them towards reformulating their educational objectives to mirror the requirements of industry.
\end{abstract}

Keywords: Student, Learning, Strategies, Performance, Carrier Development

\section{Introduction}

Education is intended to liberate the minds of the educated to enable them actualize their full potential in terms of ensuring the achievement of a desirable level of development of any community. Higher education in Ghana dates back to the pre-colonial era and gained ascendency in the postcolonial era with the establishment of universities up to the present era where there has been a proliferation of higher education institutions, many of which are either missionary owned or privately owned. The historical notion of higher education in Ghana was that students must be grounded in theories and concepts as well as in various languages majority of whom were foreign. In spite of the fact that there is said to be fallen standards in education, many students continue to graduate with very good degree classes, yet there are complaints of them not being in gainful employment. It has also been noted that the link between educational curriculum and industry has been very weak and this has been cited as one of the reasons for the current tendency of net unemployment among graduates in the country. It is not doubtful that teaching and learning strategies adopted by tertiary students and tertiary institutions may play active roles in enhancing students' academic performance but is it the same for their future carrier development, organisational achievement and by extension national development? In this 
paper, I discuss various learning strategies, the link between student learning strategies and academic performance, learning strategies and work performance and learning strategies that students recommend as the best. I concluded on the notion that education must bring out the full potential of the educated to enable them make the best contribution to national development, otherwise curriculum reform must become an absolute necessity.

\section{Background}

The development of most European and American countries can be attributed to the empirical teaching and learning strategies adopted by most of their tertiary institutions including colleges and technical institutes (Dunlosky and Hartwig, 2011). The awesome technology, inventions, creativity and innovations seen in these continents regarded as the result of an institutionalised practical oriented teaching and learning strategies in tertiary educational institutions. Teaching and learning strategies in these countries do not only maximize academic output but equip students with technical and system skills which optimize their proficiency and performance on the field of work.

Various learning strategies have been outlined and recommended by experts for use. Ding (2007: 276) justified memorized learning as a key to academic success. This follows the view of Fitzpatrick and Wray (2005) who argued that memorization is an inevitable consequence of the testing process. However, other views indicated that memorization becomes a means by which the human brain is used as a substitute for the notebook (paper or electronic) that is not permitted in the exam hall. Initially, it was a matter of avoiding reports of poor performance reaching home. Later, though, success in tests became a motivator for study, and in this regard one can infer the possibility of some measure of wash back into the teaching method (Green, 2007). The University of Kansas also outlined some strategies for learning, which may not be practical but gives students practical understanding of the concepts and theories after which they can reproduce and implement on their own based on their understanding (Kansas University Centre for Research on Learning, 2016). Most of these researches sought to address how these strategies can maximize academic output but the main focus of this research is to assess how these strategies can promote work performance and increase development and social life as well.

All these strategies have their own advantages and positive implications on the students' life, academic performance and future carrier development but the main focus of this research is to assess out of the various learning strategies, the one that will not only maximize academic output but will also increase work performance as well.

In most African countries, it is a perception that although tertiary institutions are structured to train students to acquire some practical skills and prepare them for the job markets, largely, the culture and prime interests of such institutions are still centered on promoting academic excellence after subjecting students to rigorous learning of theories and concepts without due regard to the practical application of such theories and concepts in solving real world problems.

The history of Ghana's educational institutions is replete with sterling efforts made to drive academic excellence. Historically, the main focus of tertiary educational institutions has been that students should be able to pass their exams very well by providing correct answers to questions asked in examinations notwithstanding the strategies and techniques used in learning so long as such strategies are devoid of any examination malpractices. Consequently, students graduate with excellent academic results but have little or no practical skills necessary for effective work performance. Directly and indirectly, organisational achievement is negatively affected and national development is curtailed as a result of incompetence and poor service delivery. Innovations, inventions and creativity are also minimal as a result of the adoption of inappropriate learning strategies.

It is perceived that students have the tendency of selecting out of the numerous learning strategies the one that suits them most. Apart from the individual student preferences, there is also a perception that there are instances where students are compelled by some internal and external factors including instructors/facilitators/lecturers to practice a particular learning strategy. Another perception is that students' adoption of particular learning strategies is driven by systemic factors other than their own preference and the requirements of a facilitator/instructor/lecturer.

\section{Problem Statement}

The issue of poor work performance and incompetence that affects organisational achievements, social life and national development is perceived to be a product of bad or inappropriate learning strategies adopted by employees whilst in school. Currently, Ghana is ranked among the league of countries with high levels of graduate unemployment. There have also been numerous complaints by industry that Tertiary educational institutions churn out millions of graduates each year with very excellent academic certificates without employable skills. The blame has been put squarely on students' adoption of learning strategies that facilitate academic excellence but do not have the necessary skills required by industry for good work performance. The question that I sought to answer in this study was whether there is empirical evidence linking the learning strategies that students adopted to academic performance and future work performance and what considerations do students make in deciding to adopt a particular learning strategy?

\section{Research Questions}

What factors compel students to practice particular learning strategies?

What are the effects of the various learning strategies 
adopted by students on work performance?

What type of learning strategy do students recommend as most appropriate in achieving learning their outcomes?

\section{Research Methodology}

A case study approach was adopted in conducting the study. This approach was adopted because it provided the basis for in-depth analysis of the variables under study.

\subsection{Study Population}

The primary respondents of the study were students of the Wa campus of the University for Development Studies, lecturers and management of selected organisations within the Wa Municipality.

\subsection{Sample Size}

A total of 5 undergraduate degree programmes were purposively selected out of a total of 8 for the study. In addition, 20 lecturers and management of 3 organisations were also purposively selected to participate in the study. A sample of 510 students were randomly selected across the five programmes. The selected lecturers have had extensive experience working with students and student groups of the university. The three organisations were selected because of their track record of working with student interns and former students of the university.

\subsection{Data Collection Methods and Tools}

Extensive literature relevant to the subject matter of the study was reviewed. This grounded the study in theory and practice and provided a basis for a determination of the analytical approach. Interviews were conducted in order to collect primary data for analysis towards answering the fundamental questions of the study.

\subsection{Data Analysis}

Primary data were analysed using a statistical package for social scientists (SPSS) the results of which were presented in tables, charts and graphs.

\section{Conceptual and Theoretical Perspectives}

\subsection{Learning Strategies}

There are varied conceptual and theoretical perspectives regarding learners' strategies. Cotterall and Reiders (2004) emphasized the benefit of learners' strategies, as specific actions undertaken by the learner to make learning easier, faster, more enjoyable, more self- directed, more effective, and more transferable to new situations. Oxford (2003) focused on what happens when students use the strategy of memorization as behavior. Learner strategies are very important, because they "play a crucial role in learning" and "affect the type and amount of practice" students do (Cotterall \& Reiders, 2004, p. ii). O'Malley \& Chamot (1990) on the other hand offered a useful model for describing three important learning strategies: cognitive (identifying, remembering, storing and retrieving words and sounds), metacognitive (managing and monitoring learning), and social- affective (managing feelings or interaction among learners, questioning for clarification and self- talking). Among these, the first strategy, cognitive, is of most relevance to memorisation, because it works directly with the target and involves identifying, remembering, storing, and retrieving words, sounds, or other aspects specific to the subject matter of learning. The taxonomy of learning embraces different levels including remembering, understanding, applying, analyzing, evaluating and creating (Anderson and Krathwohl, 2001). Similarly, Weimer (2016, p.5) contended that ".....when content becomes the be-all and end-all of the teaching process, when the content matters more than anything else ... faculty are prevented from using methods that enhance how much students learn". This has the tendency of hurting both students and faculty alike because the delivery may be less than appropriate and students may not comprehend the content delivered. This contention emphasis the importance of both content and the delivery process.

According to Richards, et al., (1992:226), "Memorising is the process of establishing information in memory. Memorising usually involves conscious processes. In this regard, learners are conscious of what they memorise and reflect about what is being committed into memory so that they can recall it later before applying it. This technique is similar to a description of a cognitive learning strategy called rehearsal (O'Malley \& Chamot, 1990). In my view, memorization pertains to the process of learning a distinct fact or thing through a deliberate effort. This view is in line with Orlin, (2013) who argued that memorization as a process unfolds in two basic was: raw rehearsal and mnemonics. Learning in this fashion is synonymous with rote learning, which is sometimes criticised with derogative terms such as parrot fashion, regurgitation, cramming, or mugging because the person who engages in rote learning may give the wrong impression of having understood he/she has written or said. This learning strategy is strongly discouraged by many new curriculum standards. For example, Science and Mathematics standards in the United States specifically emphasized the importance of deep understanding over the mere recall of facts (National Council of Teachers of Mathematics, 2000), which is seen to be less important, although advocates of traditional education have criticized the new American standards as slighting learning basic facts and elementary arithmetic, and replacing content with process-based skills. The National Council of Teachers of Mathematics (2000) summarized this view as follows: "when calculators can do multi-digit long division in a micro-second, graph complicated functions at the push of a button, and instantaneously calculate derivatives and integrals, serious questions arise about what is important in the mathematics curriculum and what it means to learn mathematics. More than ever, mathematics must include the mastery of concepts instead of mere memorization and the 
following of procedures. More than ever, school mathematics must include an understanding of how to use technology to arrive meaningfully at solutions to problems instead of endless attention to increasingly outdated computational tedium", which argument Quirk (2000-2011) sought to explain.

Orlin (2013) critiqued what he argued as a systematic bias in American education towards fact-based memorization. He contended that overemphasizing the memorizing of facts limits the student's ability to bind what she has learned into a "web of logic". Memorization is a frontage road: It runs parallel to the best parts of learning, never intersecting. Olson (2013) further gave credence to Orlin by asserting that "memorization is a detour around all the action, a way of knowing without learning, of answering without understanding...". From the fore-going, it is conclusive that the benefit of memorizing lies in the ability to exercise brain function but not in the application of what has been memorized in solving real world problems but what then is the essence of knowing if such knowledge cannot be translated into solutions. Learning is therefore not expected to be just an abstraction but a formidable tool for human development. However, the American Psychological Association, Coalition for Psychology in Schools and Education (2015, p.8), contended that teaching and learning are intricately linked to social and behavioral factors of human development, including cognition, motivation, social interaction, and communication. They proposed a top 20 principles for teaching and learning, which range from students beliefs or perceptions about intelligence and ability, their existing knowledge level, the learning context, degree of student practice, timely feedback, self-regulation and motivation as well as well-being and mode of assessment among others.

\subsection{Comprehensive Learning Strategy}

For Wray and Pegg, (2009), learning is more efficient when understanding is used in place of memorization but performance is affected when memorization is being totally substituted by understanding. They linked memorization and understanding with the resultant rate of performance accuracy. For them, memorization with inadequate understanding results in accurate performance, a replacement of memorization with full understanding results in inaccurate performance while understanding and trust permitting memorization leads to accurate performance. Pegg, et al., (2012) also elaborated on the learning curriculum and strategies and employability.

\subsection{Learning Strategies vs Work Performance}

Dunlosky, et al., (2013) noted that today's classroom is a reflection of the diversity of our communities and includes a mix of student interests, needs, learning styles, and cultural backgrounds. The effects of memorized learning strategy on employee's work performance is a leading factor of undeveloped and underdevelopment in many countries in the world. It is very clear that rote learning does not provide understanding of memorized theories and concept of courses. Application therefore becomes difficult for new employees' as they graduate from the universities and found themselves in the practical work world despite the class of their qualification. Dorian (2007:03-021) spelt out some effects of rote learning on employee's carrier and performance at work and its impacts on social life to include withdrawal as a result of poor performance, accidents, damage to property and deaths as a result of incompetence; poses risk to the lives of the offerees where application is human centered and retards development as a result of lack of creativity, innovations and inventions bout of lack of understanding.

Work-based learning strategies (carrier practicum), which are regarded as a distinct set of work-based learning experiences therefore support a shift in mindsets and practices around work-based learning within high school college and career pathway programs. However, it has been argued that if work-based learning experiences are to become a primary vehicle by which all students make progress towards their pathway outcomes, then educational curriculums must be: student-outcome driven rather than activity driven, for all students rather than some students, Supported by a team of academic and career-technical teachers rather than only by career-technical teachers and must be Centered in the workplace, at school, and supported by technology or a combination of all of these rather than only located in the workplace.

Conclusively, the literature elaborated the various learning strategies by focusing on how the learning strategy can maximize the students' academic output but failed to address how this strategy at long run could affect working skills and to meet organizational goals and objectives. Alison and Christine Pegg stressed so much on the effectiveness of memorized learning and comprehensive learning on the student's academic outcomes. Dorian limited his argument to the effect of rote learning on the work environment while Dunlosky laid emphasis on the need of a work-basedlearning strategy for high schools, colleges and tertiary students which is meant to prepare the student for career readiness rather than distinction in examination and also elaborated on how this could be achieved through a strategized teaching and learning procedure. The literature fell-short of recommending a learning strategy that maximizes the advantages and minimizes or eliminates the disadvantages of each learning strategy outlined. It should be noted that when learning is geared towards just ensuring that students pass examinations, some positive outcomes cannot be ruled out (Green, 2007) but there is also some degree of certainty that there will be negative consequences in performance in the work environment in the future work life of students. A good learning strategy, in my view, is thus one that maximizes academic achievement and enhances future carrier achievement and work base performance.

\section{Results}

The results of the study were arrived at based on a strict 
adherence to the methodology outlined an extensive review of the relevant literature.

\subsection{Primary Respondents Personal Data}

Out of the 510 respondents, 68 respondents representing $13.33 \%$ were level 100 students, 49 respondents representing
$9.61 \%$ were level 200 students, and 118 respondents representing $23.14 \%$ were level 300 and 265 respondents representing 51.96\% were level 400 students. This indicates that majority of the respondents were level 400 (final year students) as presented in table 1 .

Table 1. Academic level of student respondents.

\begin{tabular}{|c|c|c|c|c|c|}
\hline & Academic Level of Students & Frequency & Percent & Valid Percent & Cumulative Percent \\
\hline \multirow{5}{*}{ Valid } & 100 & 68 & 13.33 & 13.6 & 13.6 \\
\hline & 200 & 49 & 9.61 & 9.8 & 23.4 \\
\hline & 300 & 118 & 23.14 & 23.6 & 47 \\
\hline & 400 & 265 & 51.96 & 53.0 & 100 \\
\hline & Total & 500 & 98.04 & 100 & \\
\hline Missing & System & 10 & 1.96 & & \\
\hline Total & & 510 & 100 & & \\
\hline
\end{tabular}

Source: Field survey, 2016

Table 2 indicates the programme of study of respondents. A total of $50.98 \%$ of the respondents were from the Faculty of Planning and Land Management students, 33.33\% were School of Business and Law students, while 13.73\% of them were students offering Integrated Development studies from the Faculty of Integrated Development Studies.

Table 2. Programme of study of student respondents.

\begin{tabular}{llllll}
\hline & Programme & Frequency & Percent & Valid Percent & Cumulative Percent \\
\hline \multirow{6}{*}{ Valid } & Planning & 165 & 32.35 & 33.0 & 33.0 \\
& Real Estate & 95 & 18.63 & 19.0 & 52.0 \\
& IBS & 120 & 23.53 & 24.0 & 76.0 \\
& IDS & 70 & 13.73 & 14.0 & 90.0 \\
& IMS & 50 & 9.80 & 10.0 & 100.0 \\
Missing & Total & 500 & 98.04 & 100.0 & \\
Total & System & 10 & 1.96 & & \\
\hline
\end{tabular}

Source: Field survey, 2016

The learning strategies that are mostly practiced by the respondents included memorised learning, comprehensive learning strategies and practical workshops and internships which fall under work based learning. The study revealed that 350 respondents representing $68.63 \%$ practice memorized learning, $21.57 \%$ comprehend concepts and reproduce the content in their own words while $7.84 \%$ of them practice work based learning. It can be deduced from this that majority of the respondents practice memorized learning (see table 3).

Table 3. Learning strategy most preferred by the students.

\begin{tabular}{llllll}
\hline & Learning strategy & Frequency & Percent & Valid Percent & Cumulative Percent \\
\hline \multirow{4}{*}{ Valid } & Memorized learning Strategy & 350 & 68.63 & 70 & 70 \\
& Comprehend and reproduce content learnt & 110 & 21.57 & 22 & 92 \\
& Work based learning strategy (practical) & 40 & 7.84 & 100 \\
Missing & Total & System & 500 & 98.04 & 100 \\
Total & & 10 & 1.96 & \\
\hline
\end{tabular}

Source: Field survey, 2016

A cross tabulation of students' academic level and the learning strategy which they mostly adopted revealed that the number of students who adopt memorized learning strategy increases as students progressed from lower academic levels to higher levels. This trend is at variance with expectations of lecturers and facilitators across all faculties and programmes. It is expected that the number of students who practiced memorized learning would have rather reduced with academic level progression. Under normal circumstances, more and more levels 300 and 400 students who are almost at the tail end of the academic programmes should be adopting learning strategies that promote increased comprehension and practical application of concepts and theories learnt at the lower levels. This trend, perhaps, partially explains the 
disillusionment of employers regarding employee performance against set targets. It must be noted that some degree of variation was noted across the programmes.

Field survey, 2016.

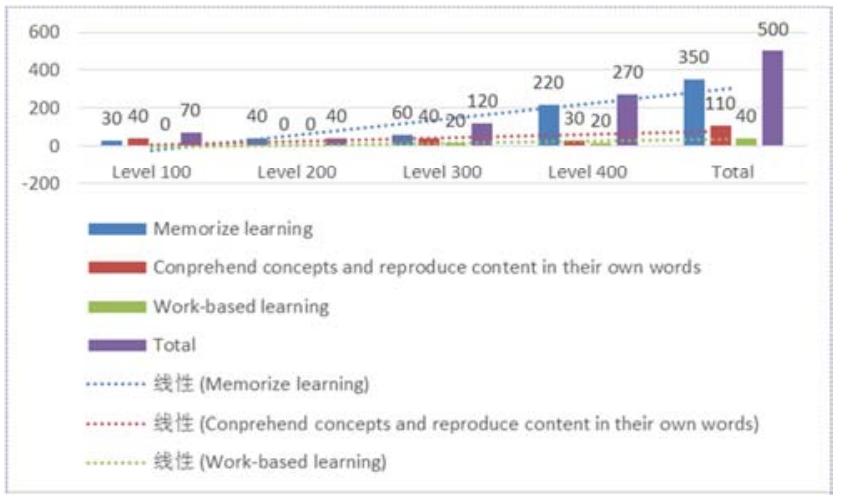

Figure 1. Academic level and learning strategies mostly used by students.

\subsection{Program of Study of Students and Learning Strategy Mostly Used}

Whereas $57.6 \%, 29.09 \%$ and $13.33 \%$ of planning students adopt memorized learning, comprehensive learning and work-based learning strategies; the situation is slightly different in the other four academic programmes. Under the Real Estate programme for instance, $68.42 \%, 21.05 \%$ and $10.53 \%$ used memorized learning, comprehensive learning and work-based learning strategies respectively; while $75.83 \%$ of IBS students indicated that their most preferred learning strategy is memorized learning, $21.66 \%$ preferred comprehensive learning strategy as opposed to only $2.5 \%$ of them who mostly used work-based learning strategy. However, in the case of IDS, $74.29 \%, 20 \%$ and $5.71 \%$ use memorized learning, comprehensive learning and work-based learning strategies respectively (see table 4).

Table 4. Academic programmes and mostly learning strategies students mostly used.

\begin{tabular}{lllll}
\hline Program of study & Memorized learning & Comprehend concept and reproduce in own words & Work based learning (practical) & Total \\
\hline Planning & 95 & 48 & 22 & 165 \\
Real Estate & 65 & 20 & 10 & 95 \\
IBS & 91 & 26 & 3 & 120 \\
IDS & 52 & 2 & 4 & 70 \\
IMS & 47 & 110 & 1 & 50 \\
Total & 350 & & 40 & 500 \\
\hline
\end{tabular}

Source: Field survey 2016

\subsection{Learning Strategy and Work Performance}

The objectives of any educational programme are the driving force its outcomes if the planned programme is well executed and managed. A total of 80 respondents admitted that their learning strategy equipped them with the required working skills, and 420 respondents also admitted that their most preferred learning strategy has not equipped them with the requisite working skills. This revelation gives credence to complaints by industry regarding the employability of graduate students in recent times.

Table 5. Student learning strategies and work performance relationship.

\begin{tabular}{llllll}
\hline & & Frequency & Percent & Valid Percent & Cumulative Percent \\
\hline & yes & 80 & 15.7 & 16.0 & 16.0 \\
Valid & no & 420 & 82.4 & 84.0 & 100.0 \\
& Total & 500 & 98.0 & 100.0 & \\
Missing & System & 10 & 2.0 & & \\
Total & & 510 & 100.0 & & \\
\hline
\end{tabular}

Source: Field survey, 2016

\subsection{Learning Strategy and Academic Output Maximization}

It was also revealed that $76.5 \%$ of students have experienced maximization of their academic performance after having adopted their most preferred learning strategy as compared with only $21.6 \%$ who did not experience any improvement in their academic achievements in relation to their preferred learning strategy over the years.

Table 6. Effect of student most preferred learning strategy on academic performance.

\begin{tabular}{|c|c|c|c|c|c|}
\hline Responses & & Frequency & Percent & Valid Percent & Cumulative Percent \\
\hline \multirow{3}{*}{ Valid } & yes & 390 & 76.5 & 78.0 & 78.0 \\
\hline & no & 110 & 21.6 & 22.0 & 100.0 \\
\hline & Total & 500 & 98.0 & 100.0 & \\
\hline Missing & System & 10 & 2.0 & & \\
\hline Total & & 510 & 100.0 & & \\
\hline
\end{tabular}

Source: Field survey, 2016 
This revelation is at variance with the relation between student most preferred learning strategy and its contribution to on the job performance. It must be noted that both lecturers/facilitators and management of industry ascribed work based learning as the most efficacious learning strategy that will maximise academic and on the job performance. The implication is that on the one hand, even though lecture deliveries may have aspects that are work based, majority of such deliveries do not actually prepare students adequately for industrial job performance. On the other hand, students always have their own reasons for adopting particular learning strategies and once they are convinced that their immediate specific objective is to excel in terms of academic performance, they pay little or no attention to suggestions by course lecturers/facilitators on the merits and demerits of their preferred learning strategy. For example, students indicated that reasons why they adopted a particular learning strategy included ease of adoption, contribution to academic achievement, nature and style of teaching. Majority of the students $(56.9 \%)$ indicated that the strategy they adopted yielded maximum academic results whereas $29.4 \%$ of them were of the opinion that they were compelled to adopt particular learning strategies based on the nature and style of teaching (see table 7).

Table 7. Reasons why students for their adoption of specific learning strategies.

\begin{tabular}{llllll}
\hline Responses & & Frequency & Percent & Valid Percent & Cumulative Percent \\
\hline & Easier to adopt & 60 & 11.8 & 12.0 & 12.0 \\
Valid & Maximizes academic achievement & 290 & 56.9 & 58.0 & 70.0 \\
& Compelled by nature and style of teaching & 150 & 29.4 & 30.0 & 100.0 \\
& Total & 500 & 98.0 & & \\
Missing & System & 10 & 2.0 & \\
Total & & 510 & 100.0 & \\
\hline
\end{tabular}

Source: Field survey, 2016

It is a general consensus that the nature and style of teaching, the nature of learning as well as the nature, style and substance of learning assessment tends to influence students in their adoption of learning strategies. Thus, there has always been the tendency to focus on aspects Anderson and Krathwohl, (2001) and neglecting the other aspects. This does not enable students to have well-rounded education to make a full contribution to society. It is therefore not surprising that majority of the students who indicated that they preferred memorised learning also related that they do so because it maximizes academic achievement. A good question then is what happens to understanding, application and creativity? Clearly, this has reflected on the opinion of students regarding the nature of teaching. For example, only $14 \%$ (70) of students were of the opinion that teaching in their programme of study was practical oriented as compared to $70 \%$ (350) who indicated that it was rather more conceptual and theoretical. The rest of the $16 \%$ (80) revealed that teaching in their programme of study was both practical and theoretical/conceptual (see table 8).

Table 8. The Nature and Style of teaching.

\begin{tabular}{|c|c|c|c|c|}
\hline \multirow{2}{*}{ Academic Programme of study } & \multicolumn{3}{|l|}{ Nature of teaching } & \multirow{2}{*}{ Total } \\
\hline & Practical oriented & Theoretical /conceptual & Both & \\
\hline Planning & 68 & 78 & 19 & 165 \\
\hline IBS & 0 & 120 & 0 & 120 \\
\hline IDS & 4 & 56 & 10 & 70 \\
\hline Real Estate & 12 & 53 & 30 & 95 \\
\hline IMS & 0 & 0 & 50 & 50 \\
\hline Total & 70 & 350 & 80 & 500 \\
\hline
\end{tabular}

Source: Field survey, 2016

\subsection{Recommended Learning Strategy}

When students were asked to respond on the learning method they will recommend provided more emphasis were not placed on academic performance and if they had the opportunity to influence on teaching and learning methodology, 58.8\% of them routed for work based learning as compared to $7.8 \%$ of them who recommended memorised learning. The rest of the students recommended comprehensive learning (see table 9).

Table 9. Learning strategies recommended by students.

\begin{tabular}{|c|c|c|c|c|c|}
\hline \multicolumn{2}{|c|}{ Recommended Strategy } & \multirow{2}{*}{$\begin{array}{l}\text { Frequency } \\
40\end{array}$} & \multirow{2}{*}{$\begin{array}{l}\text { Percent } \\
7.8\end{array}$} & \multirow{2}{*}{$\begin{array}{l}\text { Valid Percent } \\
8.0\end{array}$} & \multirow{2}{*}{$\begin{array}{l}\text { Cumulative Percent } \\
8.0\end{array}$} \\
\hline \multirow{4}{*}{ Valid } & Memorized learning & & & & \\
\hline & Comprehensive learning & 160 & 31.4 & 32.0 & 40.0 \\
\hline & work base learning (practical) & 300 & 58.8 & 60.0 & 100.0 \\
\hline & Total & 500 & 98.0 & 100.0 & \\
\hline Missing & System & 10 & 2.0 & & \\
\hline Total & & 510 & 100.0 & & \\
\hline
\end{tabular}

Source: Field survey, 2016 
The revelation above means that students are becoming more and more aware of the level of graduate unemployment which has earlier on been noted to have a bearing on their employability. This also, resonates with (Knight, et al. 2003:p5) who made an argument that when employabilityenhancing elements are only tacitly present, students' claims to employability are seriously compromised. If your project fosters achievements valued by employers, does it also ensure that learners know this?

Lecturers/facilitators/instructors and management of development institutions agreed on their relevance of concepts and theories in learning curriculums but emphasized that the application such concepts in solving problems was more relevant. They added that in some circumstances, work based learning was more preferable as that strategy involves the knowledge of relevant concepts and theories as well as their application in solving real world problems.

\section{Conclusion}

Indeed, learning programmes at the tertiary level in Ghana as in elsewhere in the world, reflect our diversity of interests either as providers of educational services, products of the educational programmes or as end users of those products. Knowledge is not gained for its own sake but to help change society positively. In the pursuit of knowledge, several factors must be worked into curriculum development including building the self-worth of students, practical skills acquisition and the creation of an interface between teaching professionals and industry on the one hand and students and industry the other hand. This, therefore calls for reexamination of the core objectives of education and tailoring the higher education process to make a full contribution to society. In addition, the link between educational institutions and industry in Africa, and in Ghana specifically must be clearly established more than ever before, and intricately woven into the educational curriculum to ensure much more progression in the key sectors of national development.

\section{References}

[1] American Psychological Association, Coalition for Psychology in Schools and Education. (2015). Center for Psychology in Schools and Education. Retrieved from http://www.apa.org/ed/schools/cpse/.

[2] Anderson, L. W., \& Krathwohl, D. R. (Eds.). (2001). A taxonomy for learning, teaching and assessing: A revision of Bloom's taxonomy of educational objectives: Complete edition. New York: Longman.

[3] Anderson, M. C. M., \& Cotterall, S. \& Reinders, H. (2004). Learner strategies. A guide for teachers. RELC Portfolio Series (edited by Renandya, W. \& Richards, J.) guide number 12. Singapore: RELC.

[4] Ding, Yanren (2007). 'Text memorization and imitation: the practices of successful Chinese learners of English', System: An International Journal of Educational Technology and
Applied Linguistics, vol. 35, pp 271-280.

[5] Dunlosky, John and Hartwig K. Marissa (2011). Study strategies of college students: Are self-testing and scheduling related to achievement? Psychonomic Society, Inc.

[6] Dunlosky, John, Rawson, Katherine A., Marsh, J. Elizabeth, Nathan, J. Mitchell and Willingham, T. Daniel (2013). Improving Students' learning with effective learning techniques: Promising directions from cognitive and educational psychology, Sage publications.

[7] Fitzpatrick, T. and Wray, A. (2005). 'Breaking up is not so hard to do: individual differences in L2 utterances in L2 utterance memorization', Canadian Modern Language Review vol. 63 , no 1, pp 35-57.

[8] Green, Anthony (2007). IELTS Wash back in Context: Preparation for Academic Writing in Higher Education. Cambridge: ESOL and Cambridge University Press.

[9] Jones, Dorian (2007-03-021). "Turkey: Revolutionizing the Classroom". Deutsche Welle. Retrieved 2008-08-1

[10] Kansas University Centre for Research on Learning (2016). Building Literacy skills for all learners. Lawrence: Kansas University.

[11] Knight, P. and Yorke, M. (2003). Assessment, Learning and Employability. London: Society for Research into Higher Education and Open University Press.

[12] National Council of Teachers of Mathematics (2000). Principles and Standards for School Mathematics. Reston: National Council of Teachers of Mathematics.

[13] Olson, Marina (2013). What Does Memorization Have To Do with Learning? In the American Conservative. Washington DC: Burr Media Group. Retrieved from www.theamericanconservative.com

[14] O'Malley, Michael J. and Chamot, Anna Uhl (1990), Learnining Strategies in second language acquisition, Cambridge University Press, Cambridge, UK.

[15] Orlin, Ben (2013). When Memorisation gets in the way of learning: A teacher's quest to discourage his students from mindlessly reciting information. Washington DC: The Atlantic Media Company. Retrieved from www.atlantic.com

[16] Oxford, Rebecca, L. (2003). Language learning styles and strategies: An overview. Proceedings of GALA (Generative Approaches to Language Acquisition) Conference, 1-25. Retrieved from http://web.ntpu.edu.tw/ language/workshop/read2.pdf.

[17] Pegg, Ann, Waldock, Jeff, Hendy-Isaac, Sonia and Ruth Lawton (2012). Pedagogy for employability. The Higher Education Academy, Heslington.

[18] Quirk, William, G. (2000-2011). Understanding the Revised NCTM Standards: Arithmetic is Still Missing! Retrieved on October 16, 2016:2:40pm

[19] Reinders, H. (2004). 'Learner strategies in the language classroom: which strategies, when and how?' Relc Guidelines, 26:1, 31-35, University of Auckland, Auckland.

[20] Richards, J. C., Platt, J. T., and Platt, H. K. (1992). Longman dictionary of language teaching and applied linguistics. Essex, England: Longman. 
[21] Weimer Maryellen (2016). Content Knowledge: A Barrier to Teacher Development. In effective strategies for improving college Teaching and learning. A special Faculty Focus report of the Teaching Professor. Magna Publications, USA.

[22] Wray, Alison and Pegg, Christine. The effect of memorized learning on the writing scores of Chinese IELTS test-takers. In: Thompson, Paul (Editor). International English Language Testing System (IELTS) Research Reports 2009: Volume 9. [Canberra]: British Council and IELTS Australia, 2009: 191216. 